\title{
Analysis of gene expression profiling of amyloidogenic immunoglobulin light-chains on cultured rat cardiomyocytes
}

\author{
FEI XU* ${ }^{*}$ YUE YU* ${ }^{*}$ FANG WANG, WEI SUN, PENG LI, HENG-FANG WU, \\ ZHI-PING BIAN, XIANG-JIAN CHEN and DONG-JIE XU
}

\author{
Department of Cardiology, First Affiliated Hospital of Nanjing Medical University, Nanjing, Jiangsu 210029, P.R. China
}

Received July 22, 2019; Accepted February 25, 2020

DOI: $10.3892 /$ etm.2020.8610

\begin{abstract}
The present study aimed to investigate the toxic effects of different amyloidogenic light-chains (LCs) on cardiomyocytes, and demonstrate the differentially expressed genes (DEGs) and signaling pathways that participate in this process. Cultured cardiomyocytes were treated with recombinant $\kappa$ LC peptide (AL-09) or with serum from a patient diagnosed with multiple myeloma ( $\lambda$ LC) with cardiac involvement. The $6 x$ His peptide or serum from healthy patients was used as peptide control or serum control, respectively. Cell viability was determined using CCK-8 assay and apoptosis was analyzed by flow cytometry. The DEGs were detected by RNA sequencing (RNA-Seq), followed by Gene Ontology and Kyoto Encyclopedia of Genes and Genomes (KEGG) analyses. Changes in gene expression levels were confirmed by reverse transcription-quantitative PCR. The cell viability in the AL-09 peptide-treated $(0.2 \mathrm{mg} / \mathrm{ml})$ and patient serum-treated (1:10 dilution) cardiomyocytes decreased to 42 and $-72 \%$ of the corresponding control groups. The extent of cell apoptosis increased in AL-09-treated cardiomyocytes compared with the control group. RNA-Seq showed 256 DEGs co-existed in the two paired groups, including 127 upregulated and 88 downregulated genes. The KEGG pathways for upregulated expressed genes included the 'TGF- $\beta$ signaling pathway', the 'Hedgehog signaling pathway', the 'ErbB signaling pathway' and 'lysine degradation'. The higher mRNA expression of bone morphogenetic protein (Bmp) 4, Bmp6, prostaglandin G/H synthase (Ptgs)1, Ptgs2, epiregulin, $T g f a$
\end{abstract}

Correspondence to: Dr Xiang-Jian Chen or Dr Dong-Jie Xu, Department of Cardiology, First Affiliated Hospital of Nanjing Medical University, 300 Guangzhou Road, Nanjing, Jiangsu 210029, P.R. China

E-mail: chenxiangjian@njmu.edu.cn

E-mail: djxu@njmu.edu.cn

${ }^{*}$ Contributed equally

Key words: cardiac amyloidosis, differentially expressed genes, transforming growth factor- $\beta$-bone morphogenetic protein signaling pathway, recombinant $\mathrm{k}$ light-chain peptide and procollagen-lysine,2-oxoglutarate 5-dioxygenase 2 were confirmed. The KEGG pathways of downregulated expressed genes included genes involved with the 'p53 signaling pathway' and the 'cell cycle'. The mRNA expression levels of E3 ubiquitin-protein ligase CCNB1IP1 showed significant downregulation in the AL-09 peptide group compared with those in the $6 \mathrm{xHis}$ peptide group. In conclusion, cardiomyocytes treated with amyloidogenic $\lambda$ and $\kappa$ LCs presented with decreased cell viability compared with controls. Cell apoptosis increased in $\kappa$ LC-treated cells compared with controls. The gene expression profiles associated with transforming growth factor- $\beta$-bone morphogenetic protein, the receptor tyrosine-protein kinase erbB-2 signaling pathways, prostaglandins, collagen production, the p53 signaling pathway and the cell cycle were altered in light-chain-treated cardiomyocytes.

\section{Introduction}

Primary amyloidosis is a systematic disease characterized by the pathological deposition of misfolded proteins known as immunoglobulin light-chains (LCs) (1). Prognosis is closely associated with the organs involved, especially the heart, which is affected in $50-80 \%$ of patients with primary amyloidosis $(2,3)$. Although this disease was identified in the mid-19th century, the mortality rate remains high, resulting from a difficult early diagnosis and few effective treatment options (4). Patients with cardiac amyloidosis usually present with symptoms of heart failure, angina and conductive delays $(3,5)$. Cardiac biomarkers, such as serum cardiac troponin and brain natriuretic peptide (BNP), are sensitive markers of cardiac dysfunction and the levels are elevated in amyloidosis $(3,5,6)$. Treatment of cardiac amyloidosis depends on a combination of therapies aimed at controlling hematologic disorders and relieving cardiac damage (5). Heart failure in cardiac amyloidosis faces specific therapeutic challenges in the clinic. The routine therapeutic paradigm of heart failure cannot be simply translated to cardiac amyloidosis (5-7). Loop diuretics are central to the treatment for relieving congestion in cardiac amyloidosis $(3,5)$. Angiotensin converting enzyme inhibitors, angiotensin receptor blockers, beta blockers and mineralocorticoid receptor antagonists can cause hypotension, renal insufficiency, or other contraindications $(3,5)$. They are often poorly tolerated and require close patient monitoring $(3,5)$. Non-dihydropyridine calcium channel blockers 
and digoxin must be avoided as they may worsen congestive heart failure or yield a risk of toxicity (5). Patients usually die from arrhythmia and congestive heart failure, and the disease has a median survival time of $<8$ months and a 5-year survival rate of $<10 \%(3-5,8)$. The disease progresses rapidly and the prognosis is poor. Thus, new strategies for treatment are required to improve the survival rate.

The pathological mechanism behind cardiac amyloidosis remains to be elucidated. A previous study confirmed that increased reactive oxygen species production in cardiomyocytes induced by LC results in apoptosis and impaired heart function (9). Moreover, altered metabolism, mitochondrial dysfunction, impaired lysosomal/autophagy activity, damaged calcium handling and altered p38 mitogen-activated protein kinase pathway signaling have been reported to play important roles in the process of cardiac dysfunction induced by cardiac amyloidosis (4-10). Recent studies revealed that impaired lysosomal and autophagy are critical for mediating amyloidogenic LC toxicity (10-13).

The present study aimed to compare the direct toxic effects of amyloidogenic LCs from various sources on cultured cardiomyocytes, determine the changes in gene expression profiles and identify common signaling pathway alterations in the pathological process of amyloidosis.

\section{Materials and methods}

AL-09 synthesis. Amyloidogenic LC variable domain protein AL-09 is a $\mathrm{k}$ LC that was first identified in a cardiac amyloidosis patient $(14,15)$. In the present study, recombinant AL-09 protein was produced as described in previous studies $(14,16)$ by Nanjing Kingsray Biotechnology Co., Ltd with a 6xHis-tag added at the N-terminus. In brief, the target gene was subcloned into the prokaryotic expression vector pET-12a (GenScript) using NdeI/BamHI, and induced by $1 \mathrm{mM}$ isopropyl B-D-1-thiogalactopyranoside in an Escherichia coli BL21 (DE3) cell expression system (GenScript). The cells were harvested and stored at $-20^{\circ} \mathrm{C}$. Thawed cells were treated with osmotic shock. AL-09 was extracted from inclusion bodies using $6 \mathrm{M}$ urea. The protein was purified using a Superdex 75 column (GE Healthcare Life Sciences) on an AKTA fast protein liquid chromatography system (GE Healthcare).

Western blotting to identify AL-09. The molecular weight and purity of AL-09 were analyzed by SDS-PAGE. Protein concentration was determined using a Bradford protein assay (Beyotime Institute of Biotechnology). Samples were stored at $-80^{\circ} \mathrm{C}$ in PBS (pH 7.4). A total of $2 \mu \mathrm{g}$ AL-09 protein was electrophoretically separated by $4-20 \%$ gradient SDS-PAGE (cat. no. M42012; GenScript) and then transferred onto polyvinylidene difluoride membranes. Following blocking in 5\% non-fat milk at room temperature for $1 \mathrm{~h}$, the membranes were incubated overnight at $4^{\circ} \mathrm{C}$ with mouse anti-His monoclonal antibody (1:4,000; cat. no. A00186; GenScript). After washing, the membranes were incubated with horseradish peroxidase (HRP)-conjugated goat anti-mouse antibody (1:5,000; cat. no. A00160; Genscript) at room temperature for $45 \mathrm{~min}$. Protein signal was detected with a LumiSensor ${ }^{\mathrm{TM}}$ Chemiluminescent HRP Substrate kit (Genscript).
Human serum collection. Human serum was collected from a 61-year-old male patient diagnosed with multiple myeloma with cardiac involvement and from a healthy 28-year-old male donor without any known disease. The biochemical test results of the healthy donor presented with normal levels during the previous routine physical examination. Formal written consents were obtained from the healthy donor and the representative of the patient. The protocols used in the present study were approved by the Medical Ethical Committee of the First Affiliated Hospital of Nanjing Medical University (Nanjing, China; approval no. 2015-SR-005).

Neonatal rat cardiomyocyte culture. Cardiomyocytes were isolated from 1- to 3-day-old male and female Sprague-Dawley rats $(n=40-50$ for each of the three independent replicate experiments), which were provided by the Experimental Animal Center of Nanjing Medical University. The two-step procedure, consisting of enzyme digestion and cardiomyocyte purification, was performed based on a previous study (17). In brief, minced ventricles were repeatedly digested in an enzyme solution, which included $0.4 \mathrm{mg} / \mathrm{ml}$ collagenase type II enzyme (Worthington Biochemical Corporation) and $0.6 \mathrm{mg} / \mathrm{ml}$ trypsin (Gibco; Thermo Fisher Scientific, Inc.). The pooled enzyme solution was centrifuged at $1,500 \mathrm{xg}$ and $37^{\circ} \mathrm{C}$ for $5 \mathrm{~min}$, and the cardiomyocyte fraction was resuspended in a solution containing horse serum (Gibco; Thermo Fisher Scientific, Inc.). Further purification of cardiomyocytes was performed using Percoll density gradient medium (Sigma-Aldrich; Merck $\mathrm{KGaA}$ ) and centrifugation at $1,500 \mathrm{x} \mathrm{g}$ and $21^{\circ} \mathrm{C}$ for $30 \mathrm{~min}$. The enriched cardiomyocytes were resuspended in DMEM (Gibco; Thermo Fisher Scientific, Inc.) supplemented with $10 \%$ horse serum and 5\% FBS (ScienCell Research Laboratories, Inc.) and $100 \mathrm{U} / \mathrm{ml}$ penicillin/streptomycin (Beyotime Institute of Biotechnology), and incubated at $37^{\circ} \mathrm{C}$ with $5 \% \mathrm{CO}_{2}$ for subsequent experiments. The study protocol was approved by the Institutional Animal Care and Use Committee of Nanjing Medical University (approval no. IACUC-1708008).

CCK-8 assay. Cells were cultured in 96-well plates at a density of $3 \times 10^{5}$ cells/well for $48 \mathrm{~h}$, followed by starvation in serum-free DMEM for 6-8 h. Cells were then randomly divided into seven groups as follows: The control group, cultured in serum-free DMEM; the P0.02 group, cultured with $0.02 \mathrm{mg} / \mathrm{ml} \mathrm{AL-09;} \mathrm{the}$ P0.1 group, cultured with $0.1 \mathrm{mg} / \mathrm{ml} \mathrm{AL-09;} \mathrm{the} \mathrm{P0.2} \mathrm{group,}$ cultured with $0.2 \mathrm{mg} / \mathrm{ml}$ AL-09; the His group, cultured with $20 \mu \mathrm{g} / \mathrm{ml} 6 \mathrm{xHis}$ peptide; the AL-10 group, cultured in $10 \%$ patient serum; and the Z-10 group, cultured in $10 \%$ healthy serum. Cells were treated for a further $48 \mathrm{~h}$ and the medium was replaced with serum-free DMEM at $100 \mu \mathrm{l} /$ well. CCK-8 solution (Dojindo Molecular Technologies, Inc.) was added (10 $\mu \mathrm{l} /$ well) to the medium and incubated at $37^{\circ} \mathrm{C}$ for $1 \mathrm{~h}$. Subsequently, the absorbance was measured at a wavelength of $450 \mathrm{~nm}$ using a microplate reader (BioTek Instruments, Inc.). Cell viability was calculated as the absorbance ratio of treated groups to the control group.

Apoptosis detection by flow cytometry. Cardiomyocytes were seeded in 24-well plates at a density of $3 \times 10^{5}$ cells/well for $48 \mathrm{~h}$, starved for 6-8 h, and cultured in serum-free DMEM, His peptide and AL-09 $(0.2 \mathrm{mg} / \mathrm{ml})$ for $48 \mathrm{~h}$. Cell apoptosis 
Table I. Primers used for reverse transcription-quantitative PCR.

\begin{tabular}{lll}
\hline mRNA & \multicolumn{1}{c}{ Forward primer } & \multicolumn{1}{c}{ Reverse primer } \\
\hline Bmp6 & 5'-GAGCTTTACGTGAGCTTCCAGGAC-3' & 5'-GGCATTCATGTGTGCATTGAGAG-3' \\
Bmp4 & 5'-GAGGAGGAAGAAGAGCAGAGC-3' & 5'-GCGACGGCAGTTCTTATTCT-3' \\
Ptgs (Cox2) & 5'-CCACTTCAAGGGAGTCTGGAACAT-3' & 5'-TATCACACACTCTGTTGTGCTCCC-3' \\
Ptgsl (Coxl) & 5'-CATTCTGCCCTCTGTACCCAAAGA-3' & 5'-GAGCTGGAGGAAATAGCCACTCAA-3' \\
Ereg & 5'-TCACAGCGACTTGCTTGACC-3' & 5'-GGCGCTGTTCAGACTTGTGG-3' \\
Tgfa & 5'-CGCACGTACACACACCAAAC-3' & 5'-TCAGTGCATCATATACAGAAGTCAGAA-3' \\
Plod2 & 5'-GGGGATCCATGCTCGCCCTGCTCTCC-3' & 5'-GGCTCGAGTTGTCTGCCAGCCGCTTATC-3' \\
Ccnb1 & 5'-CAACTGGAGGAAGAGCAGTCA-3' & 5'-CATCTGAACCTGTATTAGCCA-3' \\
Gapdh & 5'-ACCACAGTCCATGCCATCAC-3' & 5'-TCCACCACCATGTTGCTGTA-3'
\end{tabular}

Bmp, bone morphogenetic protein; Ptgs, prostaglandin G/H synthase; Ereg, epiregulin; Tgfa, transforming growth factor- $\alpha$; Plod2, procollagen-lysine,2-oxoglutarate 5-dioxygenase 2; Ccnb1, E3 ubiquitin-protein ligase CCNB1IP1.

was determined using the Annexin V-Alexa Fluor 647/propidium iodide (PI) Apoptosis Detection kit (FCMACS Co., Ltd.) according to the manufacturer's instructions. Cells were harvested and washed three times with ice-cold PBS, followed by resuspension in $300 \mu \mathrm{l}$ binding buffer. Subsequently, Annexin V-Alexa Fluor $647(5 \mu \mathrm{l})$ and PI (10 $\mu \mathrm{l})$ were added to the samples and incubated at room temperature for $15 \mathrm{~min}$ in the dark. The percentages of Annexin V-Alexa Fluor 647-positive/PI-negative cells (early apoptosis) and Annexin V-Alexa Fluor 647-positive/PI-positive cells (late apoptosis) were analyzed using flow cytometry (BD FACStation ${ }^{\mathrm{TM}}$ 6.1 software; BD FACSCalibur; BD Biosciences).

RNA sequencing (RNA-Seq), Gene Ontology (GO) and Kyoto Encyclopedia of Genes and Genomes (KEGG) pathway analyses. To identify the common changes in the gene transcription profiles in cardiomyocytes treated with amyloidogenic LCs, two pairs of groups were designed to conduct a comparative study. In one group, cardiomyocytes were cultured with $10 \%$ patient serum (AL-10) or $10 \%$ healthy serum (Z-10, as a control). In another group, cells were cultured with $0.2 \mathrm{mg} / \mathrm{ml} \mathrm{AL-09}$ or $20 \mu \mathrm{g} / \mathrm{ml}$ 6xHis peptide (as a control). Cardiomyocytes were treated for $48 \mathrm{~h}$. Total RNA was extracted from cells using TRIzol ${ }^{\circledR}$ reagent (cat. no. 15596-026; Invitrogen; Thermo Fisher Scientific, Inc.) according to the manufacturer's instructions. RNA-seq was performed at Guangzhou RiboBio Co., Ltd using a NEBNext Ultra RNA Library Prep kit for Illumina (New England BioLabs, Inc.) according to the manufacture's instructions. A HiSeq 2500 Sequencing system (Illumina, Inc.) with SE50 sequencing strategy was employed. Computational pipelines, including Tophat version 2.0.13 (https://ccb.jhu. edu/software/tophat/index.shtml) and Gfold version 1.1.2 software (http://www.tongji.edu.cn/ zhanglab/GFOLD/index. html), were employed to process the RNA-seq data. Genes were considered significantly differentially expressed if they showed $>1$-fold change and a $Q$-value of $<0.001$. The Q-value was obtained as a correction of the P-value (18). GO (http://www.geneontology.org/) and KEGG pathway analysis (http://www.genome.ad.jp/kegg) were performed using the Database for Annotation, Visualization and Integrated Discovery 6.8 (http://david.ncifcrf.gov). $\mathrm{P}<0.05$ was used as

\section{A Translation sequence of recombinant AL-09 (His tag+ $\underline{\text { Tev }}$ cleavage site $+A L-09$ )}

1 MHHHHHHENL YFQGDIQMTQ SPSSLSASVG 31DRVTITCQAS QDINNYLIWY QQKPGQAPKL 61 LIYDASTLET GVPSRFSGSG SGTEFTFTIS 91 SLQPEDLATY HCQQYDNLPY TFGQGTKLEI $121 \mathrm{KR}$

B
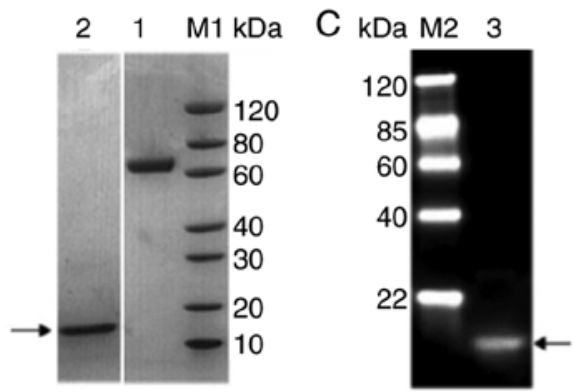

Figure 1. Physical properties of AL-09. (A) AL-09 was subcloned into Escherichia coli with the expression vector pET-12a using NdeI/BamHI. (B) Coomassie blue-stained SDS-PAGE estimated the purity of the product at $\sim 90 \%$. Lane 1, BSA $(2.00 \mu \mathrm{g})$; lane 2, AL-09 $(2.00 \mu \mathrm{g})$ and lane M2, internal reference protein. The molecular weight of AL-09 is $\sim 13.7 \mathrm{kDa}$. (C) Western blot analysis of AL-09 with the 6xHis tag. Lane 3, AL-09; lane M2, internal reference protein. AL-09, recombinant amyloidogenic light-chain protein.

the significance threshold for the enrichment degree of $\mathrm{GO}$ annotations and KEGG pathways.

Reverse transcription-quantitative $P C R$ (RT-qPCR). RT-qPCR was used to verify the RNA-seq results. Genes that demonstrated a simultaneous change in expression levels in the aforementioned two pairs of groups from the RNA-seq data were used for subsequent analysis. The primers used in the present study are listed in Table I. Cardiomyocytes were treated following the same protocol as for RNA-Seq. Total RNA was extracted from cells using TRIzol ${ }^{\circledR}$ reagent (cat. no. 15596-026; Invitrogen; Thermo Fisher Scientific, Inc.) according to the manufacturer's instructions. cDNA was synthesized using a RevertAid RT Reverse Transcription kit 


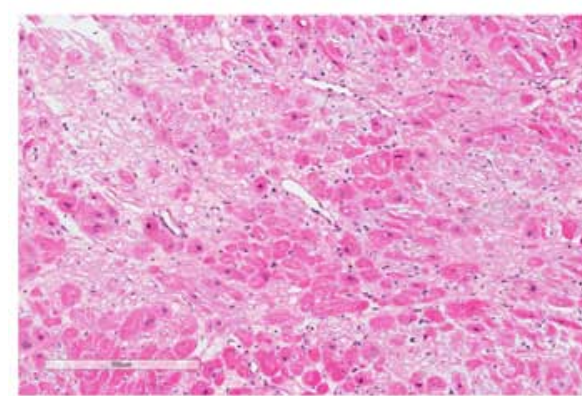

Hemotoxylin and eosin staining

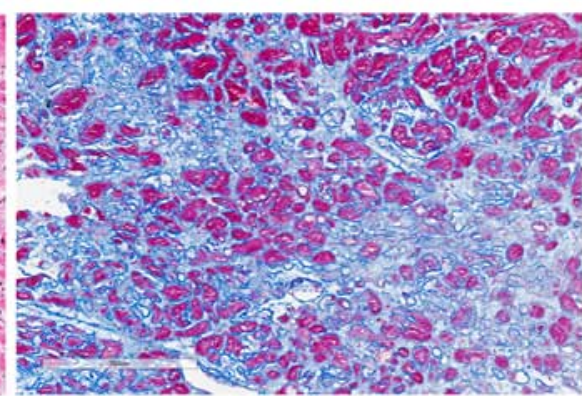

Masson's trichrome staining

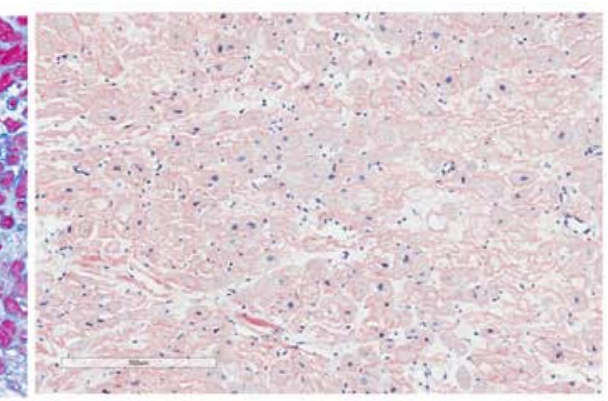

Congo red staining

Figure 2. Myocardial biopsy histological staining images. Hematoxylin and eosin staining (left panel) and Masson's trichrome staining (middle panel) showed myocardial degeneration, disordered arrangement of myocardial fibers, adipose tissue infiltration, dilation of interstitial small vessels, fibrous proliferation and hyalinization. Congo red staining (right panel) showed the presence of pink dye in the myocardium under a light microscope. Scale bar represents $300 \mu \mathrm{m}$.

(cat. no. K1691; Thermo Fisher Scientific, Inc.) according to the manufacturer's instructions. RT-qPCR was performed using the FastStart Universal SYBR Green Master (Rox) kit (cat. no. 4913850001; Roche; Merck KGaA) on a 7900 HT-Fast Real-Time PCR system (Applied Biosystems; Thermo Fisher Scientific, Inc.). The following thermocycling conditions were used for the PCR: Initial denaturation at $95^{\circ} \mathrm{C}$ for $30 \mathrm{sec}$, followed by denaturation at $95^{\circ} \mathrm{C}$ for $5 \mathrm{sec}$ and annealing and extension at $60^{\circ} \mathrm{C}$ for $30 \mathrm{sec}$ for 40 cycles. The data were analyzed according to the $2^{-\Delta \Delta \mathrm{Cq}}$ method (19). The internal reference gene GAPDH was used for normalization.

Statistical analysis. Normally distributed continuous variables are presented as the mean \pm SD. Statistical analysis was performed using GraphPad Prism 6 (GraphPad Software, Inc). Comparisons of continuous variables between groups were analyzed by unpaired Student's t-test. One-way ANOVA with Dunnett's multiple comparison post hoc test was used to compare means from different unrelated groups. $\mathrm{P}<0.05$ was considered to indicate a statistically significant difference.

\section{Results}

Recombinant amyloidogenic LC AL-09. The translation sequence of recombinant AL-09 is shown in Fig. 1A. The purity of the protein was $\sim 90 \%$, and the molecular weight was $\sim 13.7 \mathrm{kDa}$ (Fig. 1B). The AL-09 with 6xHis-tag was confirmed by western blotting (Fig. 1C), and the protein concentration was $0.4 \mathrm{mg} / \mathrm{ml}$.

Case clinic information. A 61-year-old male patient, diagnosed as suffering from multiple myeloma, restrictive cardiomyopathy, hypertension and New York Heart Association class III (7) heart failure on December 7, 2016, at the First Affiliated Hospital of Nanjing Medical University, was recruited to the present study. Bone marrow smears showed that the percentage of immature plasma cells was $10 \%$ and the presence of bone marrow hyperplasia. Immunohistochemical analysis showed that the bone marrow was positive CD38(+), CD138(+), $\kappa \mathrm{LC}(-), \lambda \mathrm{LC}(+)$, CD56 (-) and multiple myeloma oncogene $1(+)$. Serum immunofixation electrophoresis was positive for immunoglobulin G LCs. The serum and urine $\lambda$ LC levels were $1.71 \mathrm{~g} / 1$ (normal range, $0.9-2.1 \mathrm{~g} / \mathrm{l}$ ) and $200 \mathrm{mg} / 1$ (normal range, $0-3.9 \mathrm{mg} / \mathrm{l}$ ), respectively. The serum $\mathrm{N}$-terminal
A
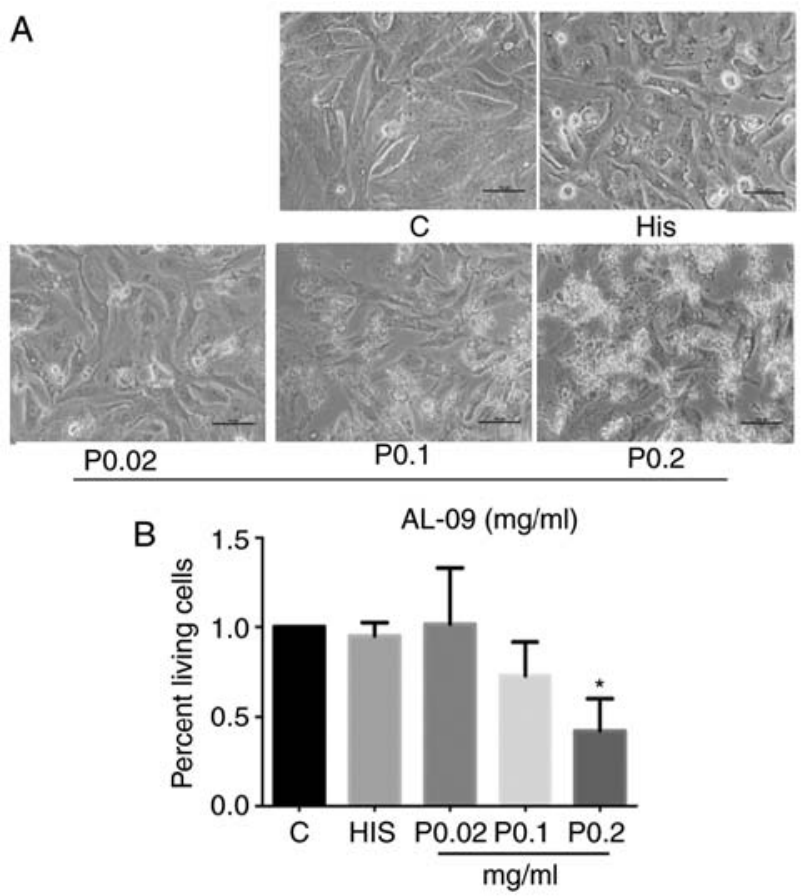

Figure 3. Morphology, viability and apoptosis of cells cultured with amyloidogenic immunoglobulin light-chain protein. (A) Cardiomyocytes cultured with AL-09 at $48 \mathrm{~h}$ observed under a light microscope (magnification, $\mathrm{x} 400$ ). (B) The viability of cardiomyocytes cultured with AL-09 $(0.2 \mathrm{mg} / \mathrm{ml})$ was significantly lower compared with that of the control group. ${ }^{*} \mathrm{P}<0.05$ vs. the control group. AL-09, recombinant amyloidogenic light-chain protein; C, control cells cultured in serum-free DMEM; HIS, cells treated with $20 \mu \mathrm{g} / 1$ His peptide; P0.02, cells treated with $0.02 \mathrm{mg} / \mathrm{ml} \mathrm{AL-09;} \mathrm{P0.1,} \mathrm{cells} \mathrm{treated}$ with $0.1 \mathrm{mg} / \mathrm{ml} \mathrm{AL-09;} \mathrm{P0.2,} \mathrm{cells} \mathrm{treated} \mathrm{with} 0.2 \mathrm{mg} / \mathrm{ml} \mathrm{AL-09.}$

(NT)-pro BNP level was 8,016 ng/l (normal range, $0-125 \mathrm{ng} / \mathrm{l}$ ). Echocardiography showed left ventricular hypertrophy, mild pericardial effusion and a left ventricular ejection fraction (LVEF) of $40.5 \%$. Myocardial perfusion imaging with $99 \mathrm{mTc}$ sestamibi at rest showed spotted sparse distribution in the left ventricle, a dilated left ventricular cavity, a diffuse decrease in wall motion and thickening of the left ventricular wall, with the LVEF at 35\%. Cardiac MRI 3T enhanced scanning presented with the following results: LVEF, 38.3\%; end systolic volume, $54.1 \mathrm{ml}$; end diastolic volume, $87.7 \mathrm{ml}$; stroke volume, $33.6 \mathrm{ml}$; cardiac output, $2.99 \mathrm{l} / \mathrm{min}$; cardiac index, $1.79 \mathrm{l} / \mathrm{min} / \mathrm{m}^{2}$ and end diastolic myocardial mass, 204.6 g. Ring-shaped high 
A

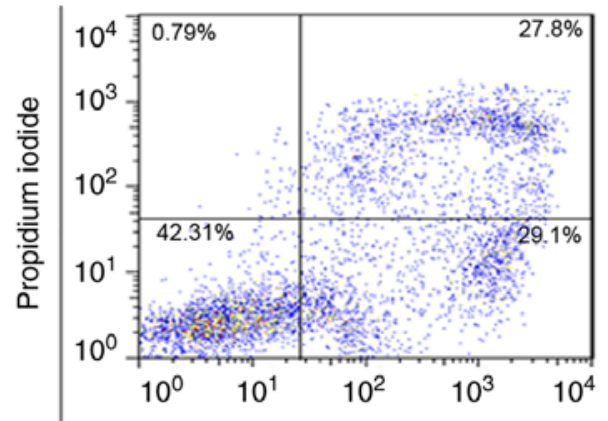

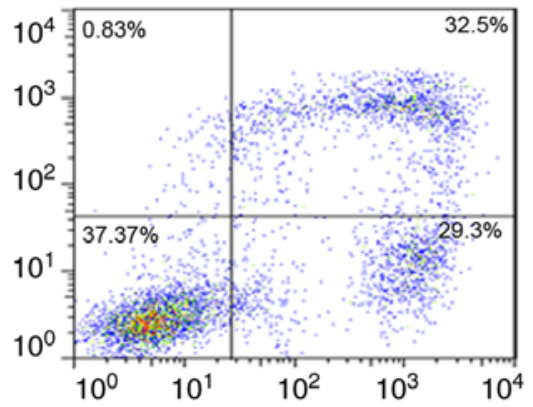

Annexin V-Alexa Fluor 647
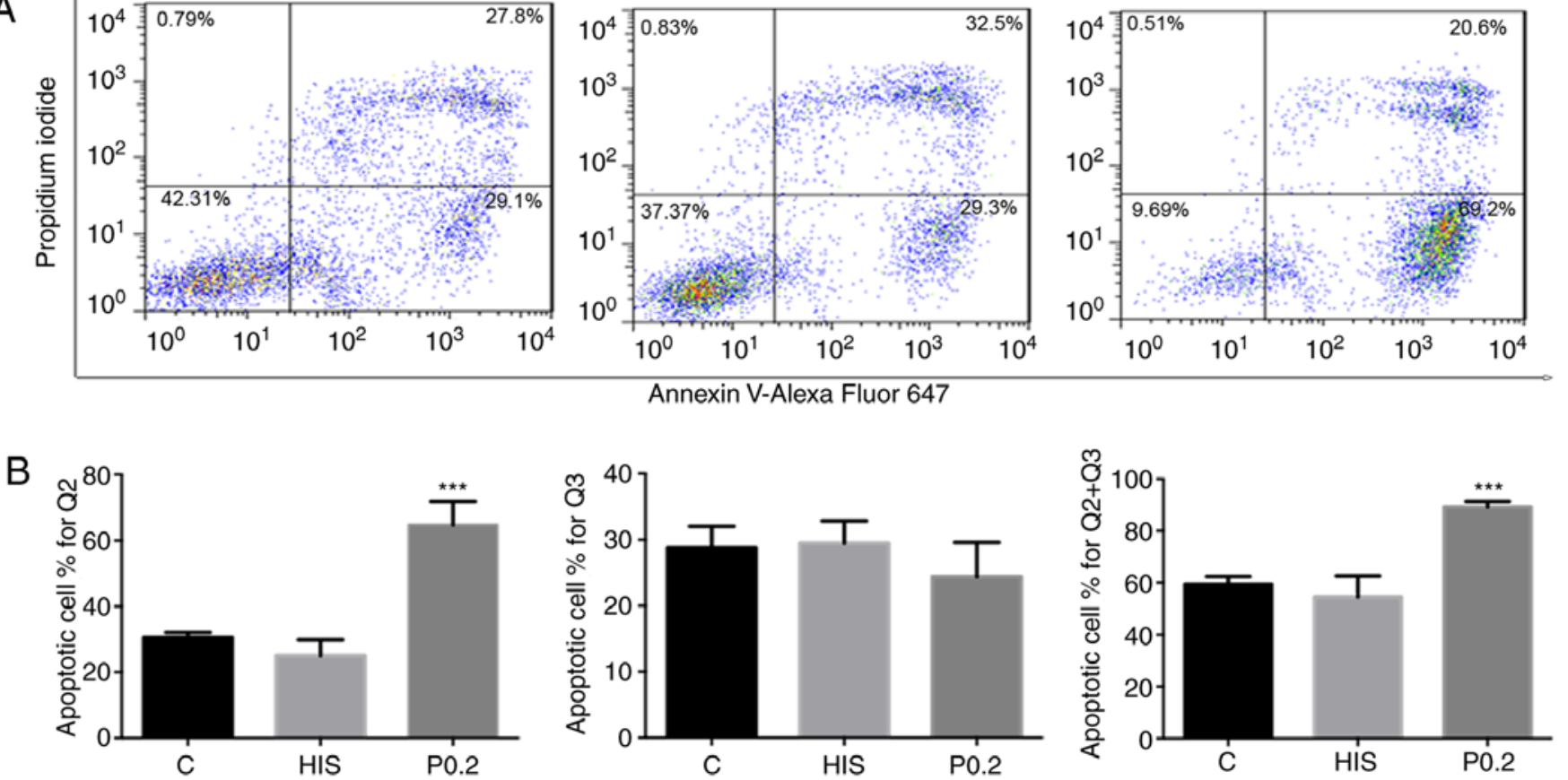

Figure 4. Flow cytometry assay results. (A) Flow cytometry charts of representative control (left panel), HIS- (middle panel) and AL-09- (P0.2; right panel) treated cells are shown. (B) Percentage of apoptotic cells in Q2 (left panel), Q3 (middle panel) and Q2+Q3 (right panel). ${ }^{* * *} \mathrm{P}<0.01$ vs. the control group. AL-09, recombinant amyloidogenic light-chain protein; C, control cells cultured in serum-free DMEM; HIS, cells treated with $20 \mu \mathrm{g} / 1$ His peptide; P0.2, cells treated with $0.2 \mathrm{mg} / \mathrm{ml} \mathrm{AL-09.}$

signal shadows were observed under the endocardium of the left and right ventricles. Hematoxylin and eosin staining and Masson's trichrome staining of myocardial biopsy specimens showed myocardial degeneration, disordered arrangement of myocardial fibers, adipose tissue infiltration, dilation of interstitial small vessels, fibrous proliferation and hyalinization. Congo red staining showed the presence of pink dye in the myocardium. The histological slides were scanned and photographed using an Aperio CS2 image capture device with Aperio ImageScope v12.3.2.7001 software (Leica Biosystems) (Fig. 2). Serum (4 ml) was collected from this patient and stored at $-80^{\circ} \mathrm{C}$ until further use. Control serum was obtained from a 28 -year old healthy male without any distinct disease at a routine physical examination.

Amyloidogenic LCs decrease cellular viability and increase apoptosis. Cultured cardiomyocytes in each group showed normal cell bodies, intact pseudopodia and high pulsation under light microscopy. Cells treated with a higher concentration of AL-09 peptide $(0.2 \mathrm{mg} / \mathrm{ml})$ showed more cellular debris compared with the control group (Fig. 3A). The results of CCK-8 assays demonstrated that the viability of cardiomyocytes cultured with AL-09 $(0.2 \mathrm{mg} / \mathrm{ml})$ decreased to $42 \%$ of the control group $(\mathrm{P}<0.05$; Fig. $3 \mathrm{~B})$. The results of flow cytometry detection were consistent with the CCK-8 assay. Cells in AL-09-treated groups presented with higher percentages of late apoptosis and total apoptotic cells compared with those in the control group $(\mathrm{P}<0.05$; Fig. 4). No significant difference was found in the percentages of early apoptotic cells between the AL-09-treated and control groups (Fig. 4).

No obvious morphological changes were observed in groups treated with human serum (data not shown). The viability of the cardiomyocytes cultured with $10 \% \mathrm{AL}$ patient serum decreased to $72 \%$ of that of the control cells cultured with $10 \%$ healthy serum $(0.72 \pm 0.07$ vs. $0.98 \pm 0.10 ; \mathrm{P}<0.05$; data not shown).

Identification of differentially expressed genes (DEGs). A total of 1,376 genes were differentially expressed in the peptide-paired group [ $\mathrm{Ph}$ (6xHis peptide group); $\mathrm{Pa}$ (AL-09 peptide group)], and 869 genes were differentially expressed in the serum-paired group [Ms (normal serum group); Mc (AL patient serum group)]. Fig. 5A and B shows GO and KEGG analyses of upregulated and downregulated DEGs co-existing in the two paired groups, respectively. Fig. 5C shows a Venn diagram of DEGs in both paired groups. A total of 256 DEGs co-existed in both paired groups by comprehensive comparison. It was found that 127 genes were upregulated and 88 genes were simultaneously downregulated in both the Ms-Mc and the Ph-Pa groups. There were 41 genes that presented different changes in the Ms-Mc and $\mathrm{Ph}-\mathrm{Pa}$ groups. Among the upregulated DEGs, the main high-enrichment GO terms regarding cardiomyocytes included 'regulation of calcium ion transport into cytosol', 'protein activation cascade', 'growth factor activity', 'dioxygenase activity' and 'anchored component of membrane'. Upregulated DEGs were involved in signal transduction, metabolism, apoptosis, adhesion and heart physiology. Upregulated KEGG pathways included 'amino sugar and nucleotide sugar metabolism', 'lysine degradation', 'TGF- $\beta$ signaling pathway' and 'ErbB signaling pathway' (Table II). The downregulated DEGs are involved in proliferation and heart functions. KEGG pathways included 'p53 signaling pathway', 'cell cycle', 'oocyte meiosis' and 'purine metabolism' (Table III). 
A

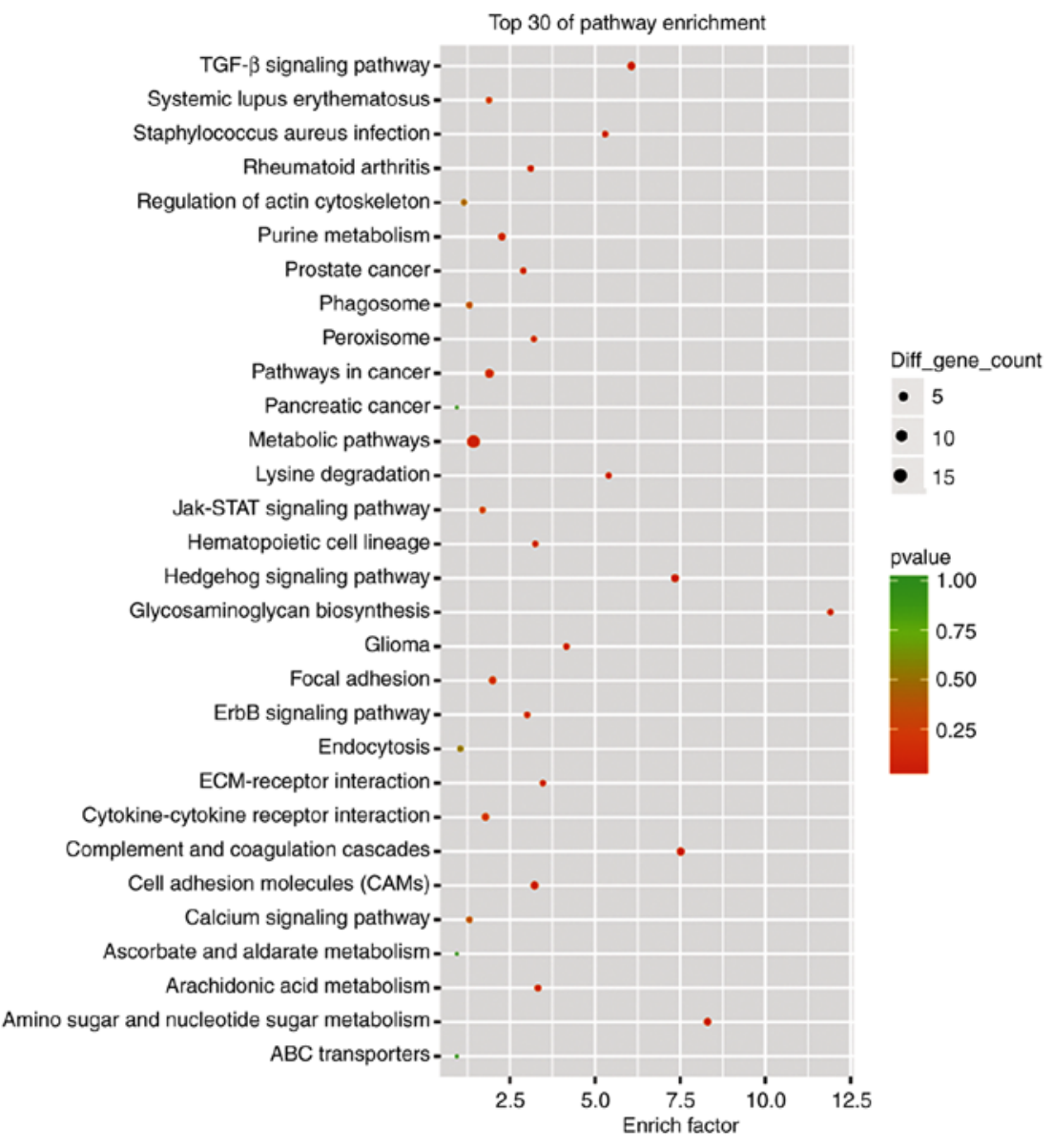

Top 30 of GO Enrichment

Viral entry into host cell -

Response to interferon-gamma

osteoblast differentiation -

Regulation of epithelial cell differentiation -

Regulation of endothelial cell proliferation -

Regulation of cytokine biosynthetic process -

Regulation of calcium ion transport into cytosol -

Protein activation cascade -

Positive regulation of osteoblast differentiation -

Placenta development -

Ovulation cycle process -

Ovarian follicle development -

Odontogenesis of dentin-containing tooth -

Odontogenesis -

Nephron development -

Negative regulation of muscle cell differentiation

Metanephros development -

Metanephric nephron development -

Memory -.

Mammary gland development -

Growth factor activity -

Glycosaminoglycan metabolic process -

Endothelial cell differentiation -

Embryonic cranial skeleton morphogenesis -

Dioxygenase activity

Complement activation

Cellular response to interleukin-1

Bone morphogenesis

Blood microparticle -

Anchored component of membrane -

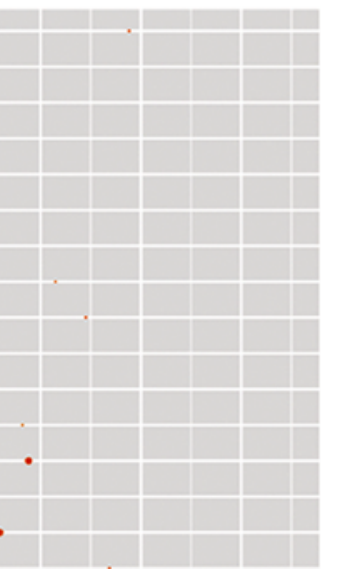

Diff_gene_count

- 4

- 5

- 6

- 7

- 8

GO_domain

- Biological_process

- Cellular_component

- Molecular_function

pvalue

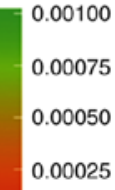

0.00100

0.00075

0.00050

0.00025

Figure 5. RNA sequencing analysis results. (A) GO and KEGG analyses of upregulated DEGs in both Ph-Pa and Ms-Mc paired groups. 
B
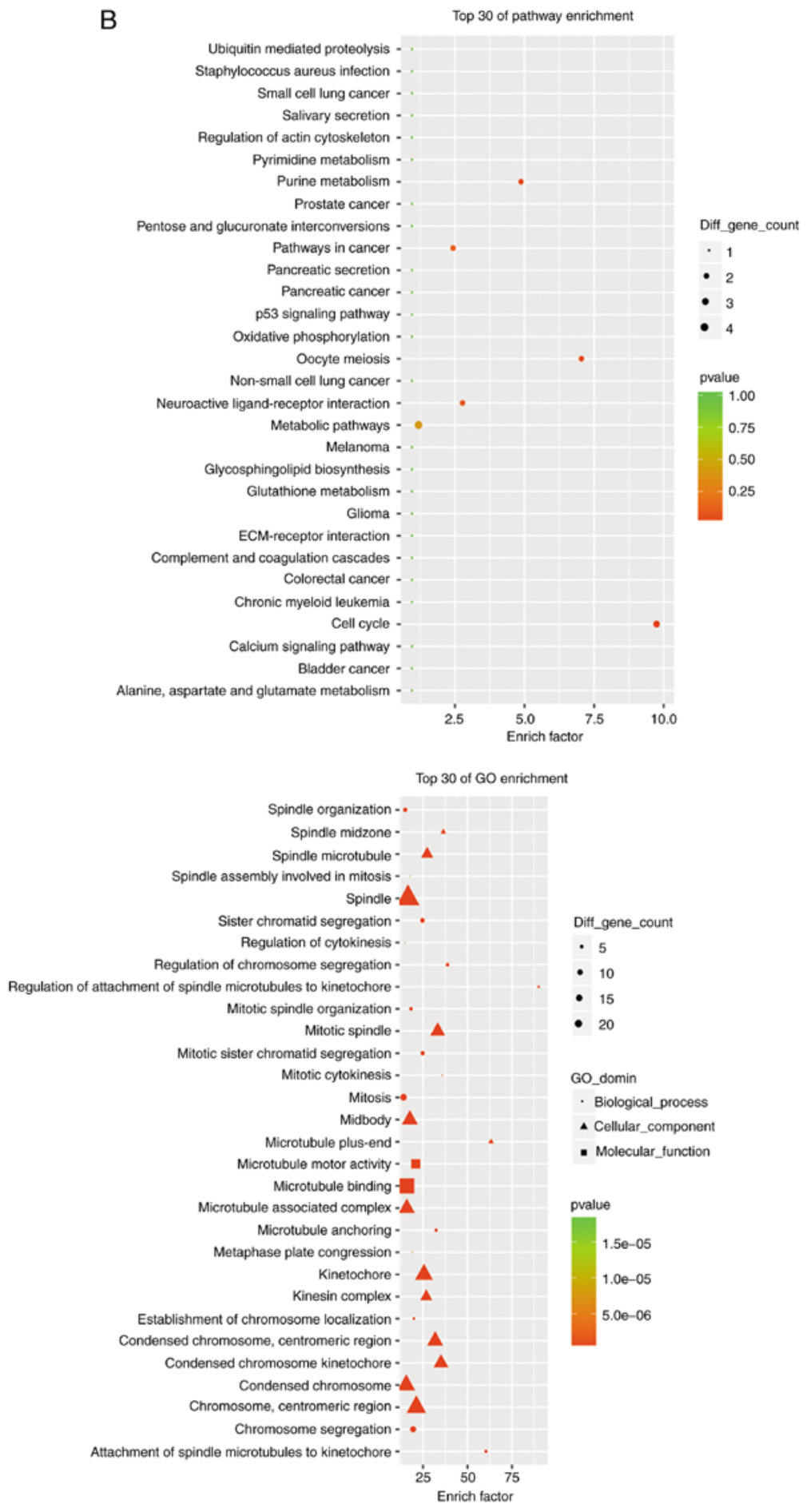

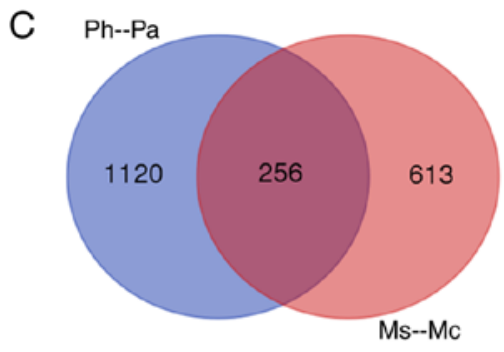

Total changes

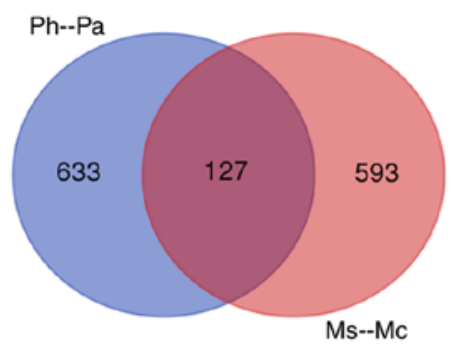

Upregulation

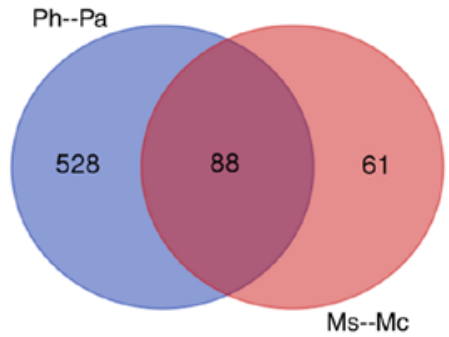

Downregulation

Figure 5. Continued. RNA sequencing analysis results. (B) GO and KEGG analyses of downregulated DEGs in both Ph-Pa and Ms-Mc paired groups. (C) Venn diagram of DEGs of both paired groups. The 256 genes, including 127 upregulated and 88 downregulated genes, were analyzed using gene enrichment pathway analysis. GO, Gene Ontology; KEGG, Kyoto Encyclopedia of Genes and Genomes; DEGs, differentially expressed genes; AL-09, recombinant amyloidogenic light-chain protein; $\mathrm{Ph}, 6 \mathrm{xH}$ is peptide group; $\mathrm{Pa}$, AL-09 peptide group; Ms, healthy serum group; Mc, AL patient serum group. 
Table II. Kyoto Encyclopedia of Genes and Genomes pathway analysis of upregulated differentially expressed genes in both paired groups.

\begin{tabular}{lll}
\hline Term & P-value & \multicolumn{1}{c}{ Genes } \\
\hline Amino sugar and nucleotide sugar metabolism & 0.0008 & Uap1, Gfpt2, Ugdh \\
Hedgehog signaling pathway & 0.0013 & Bmp4, Bmp6, Gas 1 \\
Lysine degradation & 0.0101 & Plod2, Lbp \\
Staphylococcus aureus infection & 0.0107 & Clr, Cls \\
TGF- $\beta$ signaling pathway & 0.0070 & Bmp4, Bmp6, Thbs2 \\
Glioma & 0.0203 & Pdgfra, Tgfa \\
Arachidonic acid metabolism & 0.0359 & Ptgs2, Ptgs 1 \\
Hematopoietic cell lineage & 0.0383 & Cd55, Csf1 \\
Peroxisome & 0.0396 & Xdh, Lbp \\
Rheumatoid arthritis & 0.0422 & Csfl, Angpt1 \\
ErbB signaling pathway & 0.0463 & Ereg, Tgfa \\
\hline
\end{tabular}

Table III. Kyoto Encyclopedia of Genes and Genomes pathway analysis of downregulated differentially expressed genes in both paired groups.

\begin{tabular}{lcl}
\hline Term & P-value & \multicolumn{1}{c}{ Genes } \\
\hline p53 signaling pathway & 0.0017 & Ccnb1, Rrm2 \\
Cell cycle & 0.0006 & Ccnb1, Pttg1, Cdkn2c \\
Oocyte meiosis & 0.0057 & Ccnb1, Pttg1 \\
Purine metabolism & 0.0152 & Adssl1, Rrm2 \\
\hline
\end{tabular}

Validation analysis by RT-qPCR. KEGG pathway analysis showed that among the upregulated DEGs, bone morphogenetic protein 4 (BMP4) and 6 (BMP6) were involved the 'TGF- $\beta$ signaling pathway' and the 'Hedgehog signaling pathway'. Prostaglandin G/H synthase 1 (PTGS1/COX1) and 2 (PTGS2/COX2) were associated with 'arachidonic acid metabolism'. Epiregulin (EREG) and TGFA were associated with the 'ErbB signaling pathway', and procollagen-lysine,2-oxoglutarate 5-dioxygenase 2 (PLOD2) was associated with 'lysine degradation'. In the KEGG pathway analysis of downregulated DEGs, it was shown that E3 ubiquitin-protein ligase CCNB1IP1 (CCNB1) was involved in the "p53 signaling pathway', the 'cell cycle' and 'oocyte meiosis'. The mRNA expression of eight genes (Bmp4, Bmp6, Ptgs1, Ptgs2, Ereg, Tgfa, Plod 2 and Ccnbl) was further confirmed by RT-qPCR in both paired groups. The results of RT-qPCR were consistent with the RNA-seq results (Fig. 6). The mRNA expression levels of Bmp4, Bmp6, Ptgs1, Ptgs2, Ereg, Tgfa and Plod2 were significantly upregulated in both the amyloidosis patient serum and AL-09 peptide groups compared with the levels in their respective controls. Bmp6 showed the most significant increase in the Ph-Pa group, and Ptgs2 showed the most significant increase in the Ms-Mc group. The mRNA expression levels of $C c n b l$ showed significant downregulation in the AL-09 peptide group, but no significant difference was observed in the AL patient serum group compared with their respective controls.
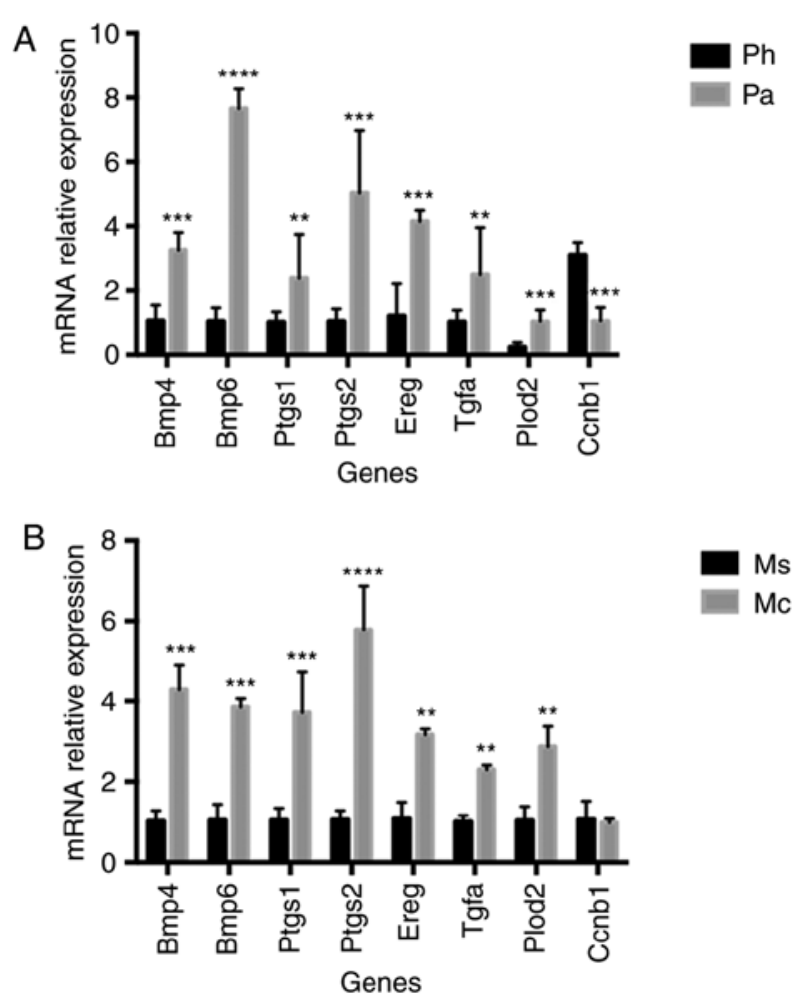

Figure 6. mRNA expression levels of eight genes (Bmp4, Bmp6, Ptgs1, Ptgs2, Ereg, Tgfa, Plod 2 and $C c n b 1)$ were determined using reverse transcription-quantitative PCR. ${ }^{* *} \mathrm{P}<0.01,{ }^{* * * *} \mathrm{P}<0.001$ and ${ }^{* * * * *} \mathrm{P}<0.0001$. vs. $\mathrm{Ph}$ or Ms groups. $\mathrm{Ph}, 6 \mathrm{xH}$ is peptide group; $\mathrm{Pa}, \mathrm{AL}-09$ peptide group; $\mathrm{Ms}$, healthy serum group; Mc, AL patient serum group; Bmp, bone morphogenetic protein; Ptgs, prostaglandin G/H synthase; Ereg, epiregulin; Tgfa, transforming growth factor- $\alpha$; Plod2, procollagen-lysine,2-oxoglutarate 5-dioxygenase 2; Ccnb1, E3 ubiquitin-protein ligase CCNB1IP1.

\section{Discussion}

Cardiac amyloidosis often occurs due to myocardial infiltration by immunoglobulin proteins, such as in LC amyloidosis, which is the most common form of systemic amyloidosis (3). Cardiac amyloidosis often confers a poor prognosis, particularly in patients affected by systemic amyloidosis (3). In the 
present study, the patient diagnosed with multiple myeloma was characterized by the presence of bone marrow hyperplasia, with a higher percentage of immature plasma cells. The plasma cells produced immunoglobulin G LCs, predominantly the $\lambda$ variant. The patient presented with notably higher urine $\lambda$ LC levels. The amyloidogenic LC underwent extracellular misfolding, aggregated into soluble oligomers and amyloid fibrils, and was deposited within the heart. Histology of the myocardial biopsy confirmed cardiac amyloidosis. The patient experienced heart failure, as demonstrated by echocardiography, radionuclide myocardial perfusion imaging and cardiac MR 3T enhanced scanning. The level of serum NT-pro BNP, a biomarker for heart failure, was increased to 8,016 ng/l, which predicted a poor prognosis for the patient (3).

AL amyloidosis is lethal due to the presence of the toxic $\mathrm{LC}$ and not as a result of the malignant behavior of the plasma cell clones (3). The present study was designed to investigate the toxic effects of LCs from various sources on cardiomyocytes. The serum of the aforementioned patient was isolated, added to the culture medium of cardiomyocytes and compared with serum from a healthy subject. Cells treated with patient serum presented with decreased cellular viability. AL-09 is a variant of the $\kappa \mathrm{LC}$ protein, which has proven to be a major contributing protein to the development of myocardial amyloid plaques (11). Recombinant AL-09 was prepared with a 6xHis tag. Cultured cardiomyocytes were treated with recombinant AL-09 peptide and 6xHis peptide. Cells treated with recombinant AL-09 peptide presented with decreased cellular viability and a higher percentage of apoptotic cells. The results indicated that the $\lambda$ and $\kappa$ amyloidogenic LCs were directly harmful to the cultured cells.

To identify common signaling pathway alterations from the toxic $\lambda / \kappa$ LCs on cardiomyocytes, the results of RNA-seq of two paired groups (recombinant AL-09 peptide versus 6xHis peptide; serum from the AL patient versus serum from the healthy subject) were analyzed. The present study focused on the DEGs that co-exist in both paired groups, which were involved in signal transduction, metabolism, cell proliferation, cell apoptosis, cellular adhesion and heart physiology. The KEGG pathways for the upregulated genes included the 'TGF- $\beta$ signaling pathway', 'lysine degradation', the 'Hedgehog signaling pathway' and the 'ErbB signaling pathway'. The KEGG pathways for downregulated genes included the 'p53 signaling pathway' and the 'cell cycle'. No concordant change on genes involved in autophagy/lysosomal was found in either paired group.

The TGF- $\beta$-BMP signaling pathway plays an important role in cell proliferation, apoptosis and fibrosis (20). TGF- $\beta$ can induce endothelial cell inflammation, proliferation and migration, and the immune response, as well as enhancing the synthesis of extracellular matrix proteins $(20,21)$. TGF- $\beta$ and/or BMP6 can promote hepatocyte apoptosis and fibrosis (22). Activation of the TGF- $\beta$-BMP signaling pathway promotes neuronal apoptosis in Alzheimer's disease (AD) (23). The dysfunction of cerebral blood vessels and cognitive deficits were shown to be reversed in a study inhibiting the TGF- $\beta$ signaling pathway (24). In the cardiovascular system, the TGF- $\beta$ signaling pathway is involved in the development of myocardial hypertrophy and extracellular matrix deposition/remodeling, and in the promotion of apoptosis and heart failure (25). Therefore, inhibition of the TGF- $\beta$-BMP pathway reduces the progression of cardiac remodeling and aids in reducing the risk of heart failure $(26,27)$. Activation of the TGF- $\beta$-BMP signaling pathway plays a role in the development of amyloid cardiomyopathy. The present study confirmed that Bmp4 and Bmp6 gene expression levels were both increased in AL-09 peptide-treated and patient serum-treated cardiomyocytes compared with the levels in their respective controls, suggesting the activation of the TGF- $\beta$-BMP signaling pathway. BMP4 and BMP6 are members of the TGF- $\beta$ superfamily; they bind with BMP receptors on the surface of the cell membrane, and are involved in a variety of signal transduction pathways such as maintaining homeostasis, regulating hormone levels and controlling tissue growth and development $(20,27)$. BMP4 induces cardiomyocyte hypertrophy and apoptosis by activating the JNK signaling pathway and altering the in vivo redox state $(28,29)$. BMP6 is involved in the pathophysiology of chronic heart failure (30). Increasing BMP6 expression, induced by TGF activation, promotes tissue fibrosis and new vascular development, as well as inhibiting cell proliferation $(22,31,32)$. The decreased cell viability and increased apoptosis observed in the present study may in part be due to the activation of the TGF- $\beta$-BMP signaling pathway, which may be a target for treating cardiac amyloidosis.

Prostaglandins are involved in AD, another disease characterized by extracellular deposition of the amyloid $\beta$-peptide (33). The disease is also characterized by the appearance of extensive neuronal loss, intracellular neurofibrillary tangles and changes in synapses of the hippocampus and cerebral cortex (33). The inflammatory pathways are activated by these processes, and the production of inflammatory mediators, including cytokines and prostaglandins, is induced by microglia, astrocytes and infiltrating leukocytes (33). Prostaglandins are small arachidonic acid-derived lipids from multi-enzymatic pathways in which COXs and phospholipases act in a rate-limiting capacity (33). COXs, also known as PTGSs, include two isozymes: A constitutive PTGS1 (COX1) and an inducible PTGS2 (COX2) (33). The pharmacological blockade of PTGS has been demonstrated to reverse the progression of AD (34). To the best of our knowledge, no study has proven that PTGSs are also activated in cardiac amyloidosis. Prostaglandins and PTGSs might exhibit similar effects in both the central nervous and cardiovascular systems. In the present study, Ptgs 1 and Ptgs 2 gene expression levels were both increased in the AL-09 peptide-treated and patient serum-treated cardiomyocytes, which suggested that there was an increased production of prostaglandins. Further studies on the role of PTGSs and prostaglandins in amyloid cardiomyopathy may contribute to development of successful therapeutic strategies.

EREG is a secreted peptide hormone that belongs to the epidermal growth factor (EGF) family (35). EREG binds to the EGF receptor (EGFR) and ErbB4, and can stimulate signaling of ErbB2 and ErbB3 through ligand-induced heterodimerization with a cognate receptor (35). EREG has functions in a variety of biological processes, including wound healing, inflammation, oocyte maturation and tissue repair, by regulating angiogenesis and vascular remodeling, as well as by stimulating cell proliferation (35). TGF- $\alpha$ is another ligand for EGFR (36). TGF- $\alpha$ is responsible for 
activating a cell proliferation, differentiation and development signaling pathway. A study on AD confirmed that accumulated amyloid $\beta$ interacts with the ErbB signaling pathway (37). To the best of our knowledge, no study has demonstrated that the ErbB signaling pathway is involved in cardiac amyloidosis. In the present study, abnormal ErbB signaling was elicited both in the AL-09 peptide-treated and patient serum-treated cardiomyocytes. The upregulation of Ereg and $T g f a$ gene expression levels were confirmed using RT-qPCR. However, the underlying mechanisms remain to be elucidated.

The myocardial extracellular space is a complicated and dynamic environment that is essential for the normal structure and function of the heart (38). The physiological pathways that regulate normal collagen turnover control and the pathological development of fibrosis are slowly being understood (38). The myocardial biopsy with Masson's trichrome stain from the patient in the present study showed abundant collagen accumulation. Lysyl hydroxylases 2 (encoded by the Plod 2 gene) is a vital enzyme that mediates stabilized collagen crosslink formation; it is localized to the cisternae of the rough endoplasmic reticulum and catalyzes the lysyl residues hydroxylation in collagen-like peptides (39). The consequent hydroxylysyl groups become sites of carbohydrate adherence in collagen and are therefore essential for intermolecular crosslink stability (39). The effect of PLOD2 on cancer has been previously reviewed (39). In the present study, Plod 2 mRNA levels were upregulated both in AL-09 peptide-treated and patient serum-treated cardiomyocytes, which in turn may contribute to abnormal collagen accumulation in cardiac amyloidosis.

Based on KEGG pathway analysis of downregulated DEGs, the 'p53 signaling pathway', the 'cell cycle', 'oocyte meiosis' and 'purine metabolism' were listed as associated terms for both the AL-09 peptide-treated and patient serum-treated cardiomyocytes. CCNB1 was shown to be involved in the 'p53 signaling pathway', the 'cell cycle' and 'oocyte meiosis'. CCNB1 is a regulatory protein that is involved in mitosis and is required for the correct control of the $\mathrm{G}_{2} / \mathrm{M}$ transition in the cell cycle. The p53 tumor suppressor prevents this transition by decreasing the intracellular CCNB1 protein levels and attenuating the CCNB1 promoter activity (40). A previous study showed that amyloid- $\beta$ directly binds to cyclin B1 in $\mathrm{AD}$ (41). In amyloidosis, cyclin D1 was identified as a prominent driver of the disease (42). In the present study, RNA-seq results shown that $C c n b 1$ gene expression decreased both in the AL-09 peptide and the AL patient serum groups compared with their respective controls. RT-qPCR results validated that the mRNA expression levels of $C c n b 1$ statistically decreased in peptide-treated group, but no significant difference was observed in the AL patient serum group compared with their respective controls. Further investigation is needed to explain the discrepancy. The underlying mechanism of action behind the link between cyclins and amyloidosis needs to be further elucidated.

In conclusion, the present study confirmed that amyloidogenic LCs ( $\lambda$ and $\kappa$ ) from different sources may directly damage the viability of cultured cardiomyocytes and promote cell apoptosis. A total of 256 DEGs co-existed both in the $\lambda$ and $\kappa$ LC-treated cardiomyocytes, of which 127 genes were upregulated and 88 genes were downregulated. The TGF- $\beta$-BMP signaling pathway, the ErbB signaling pathway, prostaglandins and collagen production were activated in LC-treated cardiomyocytes, with higher mRNA expression levels of Bmp4,Bmp6, Ptgs1, Ptgs2, Ereg, $T g f a$ and Plod 2 observed. The p53 signaling pathway and the cell cycle were hindered, characterized by decreasing Ccnbl gene expression levels. A limitation of the present study was that the recombinant AL-09 protein was only confirmed using SDS-PAGE and western blotting. No mass spectrometry or other biochemical analysis was performed. Meanwhile, in vivo experiments were not performed and protein expression changes were not investigated, which would be beneficial to confirm the reported changes. There were also no functional experiments for the associated pathways. Further studies are needed to demonstrate the underlying mechanism of action behind the gene alterations and cardiac amyloidosis, and thus to provide biomarkers for diagnosis and to help develop improved treatment strategies.

\section{Acknowledgements}

Not applicable.

\section{Funding}

This study was supported by the Open Project of Jiangsu Commission of Health (grant no. XK05200903).

\section{Availability of data and materials}

The datasets used and/or analyzed during the current study are available from the corresponding author on reasonable request.

\section{Authors' contributions}

FX, XC and DX designed the study. FX, YY, PL and ZB performed the experiments. FX, FW, WS and DX collected clinical data. FX, HW and XC analyzed the results. FX, XC, HW and DX wrote the manuscript. All authors read and approved the final manuscript.

\section{Ethics approval and consent to participate}

The clinical study was approved by Medical Ethical Committee of the First Affiliated Hospital of Nanjing Medical University (approval no. 2015-SR-005). Formal written consent was obtained from the healthy donor and the representative of the patient. The research on experimental animals was approved by the Institutional Animal Care and Use Committee of Nanjing Medical University (approval no. IACUC-1708008).

\section{Patient consent for publication}

Not applicable.

\section{Competing interests}

The authors declare that they have no competing interests. 


\section{References}

1. Liao R, Jain M, Teller P, Connors LH, Ngoy S, Skinner M, Falk RH and Apstein CS: Infusion of light chains from patients with cardiac amyloidosis causes diastolic dysfunction in isolated mouse hearts. Circulation 104: 1594-1597, 2001.

2. Guan J, Mishra S, Shi J, Plovie E, Qiu Y, Cao X, Gianni D, Jiang B, Del Monte F, Connors LH, et al: Stanniocalcin1 is a key mediator of amyloidogenic light chain induced cardiotoxicity. Basic Res Cardiol 108: 378, 2013.

3. Aimo A, Buda G, Fontana M, Barison A, Vergaro G, Emdin M and Merlini G: Therapies for cardiac light chain amyloidosis: An update. Int J Cardiol 271: 152-160, 2018.

4. Shi J, Guan J, Jiang B, Brenner DA, Del Monte F, Ward JE, Connors LH, Sawyer DB, Semigran MJ, Macgillivray TE, et al Amyloidogenic light chains induce cardiomyocyte contractile dysfunction and apoptosis via a non-canonical p38alpha MAPK pathway. Proc Natl Acad Sci USA 107: 4188-4193, 2010.

5. Tuzovic M, Yang EH, Baas AS, Depasquale EC, Deng MC, Cruz D and Vorobiof G: Cardiac amyloidosis: Diagnosis and treatment strategies. Curr Oncol Rep 19: 46, 2017.

6. Tanaka K, Essick EE, Doros G, Tanriverdi K, Connors LH, Seldin DC and Sam F: Circulating matrix metalloproteinases and tissue inhibitors of metalloproteinases in cardiac amyloidosis J Am Heart Assoc 2: e005868, 2013.

7. WRITING COMMITTEE MEMBERS, Yancy CW, Jessup M, Bozkurt B, Butler J, Casey DE Jr, Drazner MH, Fonarow GC, Geraci SA, Horwich T, et al: $2013 \mathrm{ACCF} / \mathrm{AHA}$ guideline for the management of heart failure: A report of the American College of Cardiology Foundation/American Heart Association Task Force on practice guidelines. Circulation 128: e240-e327, 2013.

8. Lavatelli F, Imperlini E, Orru S, Rognoni P, Sarnataro D, Palladini G, Malpasso G, Soriano ME, Di Fonzo A Valentini $\mathrm{V}$, et al: Novel mitochondrial protein interactors of immunoglobulin light chains causing heart amyloidosis. FASEB J 29: 4614-4628, 2015.

9. Brenner DA, Jain M, Pimentel DR, Wang B, Connors LH, Skinner M, Apstein CS and Liao R: Human amyloidogenic light chains directly impair cardiomyocyte function through an increase in cellular oxidant stress. Circ Res 94: 1008-1010, 2004

10. Imperlini $E$, Gnecchi M, Rognoni $P$, Sabidò E, Ciuffreda MC Palladini G, Espadas G, Mancuso FM, Bozzola M, Malpasso G, et al: Proteotoxicity in cardiac amyloidosis: Amyloidogenic light chains affect the levels of intracellular proteins in human heart cells. Sci Rep 7: 15661, 2017.

11. Guan J, Mishra S, Qiu Y, Shi J, Trudeau K, Las G, Liesa M, Shirihai OS, Connors LH, Seldin DC, et al: Lysosomal dysfunction and impaired autophagy underlie the pathogenesis of amyloidogenic light chain-mediated cardiotoxicity. EMBO Mol Med 6: 1493-1507, 2014.

12. Pattison JS and Robbins J: Protein misfolding and cardiac disease: Establishing cause and effect. Autophagy 4: 821-823, 2008

13. Edwards HV, Cameron RT and Baillie GS: The emerging role of HSP20 as a multifunctional protective agent. Cell Signal 23: 1447-1454, 2011

14. Sikkink LA and Ramirez-Alvarado M: Cytotoxicity of amyloidogenic immunoglobulin light chains in cell culture. Cell Death Dis 1: e98, 2010

15. McLaughlin RW, De Stigter JK, Sikkink LA, Baden EM and Ramirez-Alvarado M: The effects of sodium sulfate, glycosaminoglycans, and Congo red on the structure, stability, and amyloid formation of an immunoglobulin light-chain protein. Protein Sci 15: 1710-1722, 2006.

16. Baden EM, Owen BA, Peterson FC, Volkman BF, Ramirez-Alvarado $\mathrm{M}$ and Thompson JR: Altered dimer interface decreases stability in an amyloidogenic protein. J Biol Chem 283: 15853-15860, 2008

17. Louch WE, Sheehan KA and Wolska BM: Methods in cardiomyocyte isolation, culture, and gene transfer. J Mol Cell Cardiol 51: 288-298, 2011.

18. Audic S and Claverie JM: The significance of digital gene expression profiles. Genome Res 7: 986-995, 1997.

19. Livak KJ and Schmittgen TD: Analysis of relative gene expression data using real-time quantitative PCR and the 2(-Delta Delta C(T)) method. Methods 25: 402-408, 2001.

20. Danilewicz $M$ and Wagrowska-Danilewicz $M$ : Immunohistochemical analysis of transforming growth factor beta-1 in AA and AL renal amyloidosis. Pol J Pathol 57: 193-198, 2006.
21. Weiss R, Lifshitz V and Frenkel D: TGF- $\beta 1$ affects endothelial cell interaction with macrophages and $\mathrm{T}$ cells leading to the development of cerebrovascular amyloidosis. Brain Behav Immun 25: 1017-1024, 2011.

22. Lam HB, Yeh CH, Cheng KC, Hsu CT and Cheng JT: Effect of cholinergic denervation on hepatic fibrosis induced by carbon tetrachloride in rats. Neurosci Lett 438: 90-95, 2008.

23. Adams SL, Benayoun L, Tilton K, Mellott TJ, Seshadri S, Blusztajn JK and Delalle I: Immunohistochemical analysis of activin receptor-like kinase 1 (ACVRL1/ALK1) expression in the rat and human hippocampus: Decline in CA3 during progression of Alzheimer's disease. J Alzheimers Dis 63: 1433-1443, 2018.

24. Papadopoulos P, Tong XK, Imboden H and Hamel E: Losartan improves cerebrovascular function in a mouse model of Alzheimer's disease with combined overproduction of amyloid-beta and transforming growth factor- $\beta 1$. J Cereb Blood Flow Metab 37: 1959-1970, 2017.

25. Dobaczewski M, Chen W and Frangogiannis NG: Transforming growth factor (TGF)- $\beta$ signaling in cardiac remodeling. J Mol Cell Cardiol 51: 600-606, 2011.

26. Villar AV, García R, Llano M, Cobo M, Merino D, Lantero A, Tramullas M, Hurlé JM, Hurlé MA and Nistal JF: BAMBI (BMP and activin membrane-bound inhibitor) protects the murine heart from pressure-overload biomechanical stress by restraining TGF- $\beta$ signaling. Biochim Biophys Acta 1832: 323-335, 2013

27. Wu F, Yao H, Bader A, Dong F, Zhu F, Wu N, Wang B, Li H, Brockmeyer NH and Altmeyer P: Decorin gene transfer inhibited the expression of TGFbeta1 and ECM in rat mesangial cells. Eur J Med Res 12: 360-368, 2007.

28. Lu J, Sun B, Huo R, Wang YC, Yang D, Xing Y, Xiao XL, Xie X and Dong DL: Bone morphogenetic protein-2 antagonizes bone morphogenetic protein-4 induced cardiomyocyte hypertrophy and apoptosis. J Cell Physiol 229: 1503-1510, 2014.

29. Wu X, Sagave J, Rutkovskiy A, Haugen F, Baysa A, Nygård S, Czibik G, Dahl CP, Gullestad L, Vaage J and Valen G: Expression of bone morphogenetic protein 4 and its receptors in the remodeling heart. Life Sci 97: 145-154, 2014.

30. Banach J, Gilewski W, Slomka A, Buszko K, Błażejewski J, Karasek D, Rogowicz D, Żekanowska E and Sinkiewicz W: Bone morphogenetic protein 6-a possible new player in pathophysiology of heart failure. Clin Exp Pharmacol Physiol 43: 1247-1250, 2016.

31. Knittel T, Fellmer P, Muller L and Ramadori G: Bone morphogenetic protein- 6 is expressed in nonparenchymal liver cells and upregulated by transforming growth factor-beta 1. Exp Cell Res 232: 263-269, 1997.

32. Yano R, Golbar HM, Izawa T, Sawamoto O, Kuwamura M and Yamate J: Participation of bone morphogenetic protein (BMP)-6 and osteopontin in cisplatin (CDDP)-induced rat renal fibrosis. Exp Toxicol Pathol 67: 99-107, 2015.

33. Fattahi MJ and Mirshafiey A: Positive and negative effects of prostaglandins in Alzheimer's disease. Psychiatry Clin Neurosci 68: 50-60, 2014

34. Bitto A, Giuliani D, Pallio G, Irrera N, Vandini E, Canalini F, Zaffe D, Ottani A, Minutoli L, Rinaldi M, et al: Effects of COX1-2/5-LOX blockade in Alzheimer transgenic 3xTg-AD mice. Inflamm Res 66: 389-398, 2017.

35. Riese DJ II and Cullum RL: Epiregulin: Roles in normal physiology and cancer. Semin Cell Dev Biol 28: 49-56, 2014.

36. Singh B, Carpenter G and Coffey RJ: EGF receptor ligands: Recent advances. F1000Res 5: F1000, 2016.

37. Zhang H, Zhang L, Zhou D, He X, Wang D, Pan H, Zhang X, Mei Y, Qian Q, Zheng T, et al: Ablating ErbB4 in PV neurons attenuates synaptic and cognitive deficits in an animal model of Alzheimer's disease. Neurobiol Dis 106: 171-180, 2017.

38. White SK, Sado DM, Flett AS and Moon JC: Characterising the myocardial interstitial space: The clinical relevance of non-invasive imaging. Heart 98: 773-779, 2012

39. Du H, Pang M, Hou X, Yuan S and Sun L: PLOD2 in cancer research. Biomed Pharmacother 90: 670-676, 2017.

40. Innocente SA, Abrahamson JL, Cogswell JP and Lee JM: p53 regulates a G2 checkpoint through cyclin B1.Proc Natl Acad Sci USA 96: 2147-2152, 1999.

41. Milton NG: The amyloid-beta peptide binds to cyclin B1 and increases human cyclin-dependent kinase-1 activity. Neurosci Lett 322: 131-133, 2002

42. da Silva Filho MI, Försti A, Weinhold N, Meziane I, Campo C, Huhn S, Nickel J, Hoffmann P, Nöthen MM,Jöckel KH, et al: Genome-wide association study of immunoglobulin light chain amyloidosis in three patient cohorts: Comparison with myeloma. Leukemia 31: 1735-1742, 2017.

This work is licensed under a Creative Commons Attribution-NonCommercial-NoDerivatives 4.0 International (CC BY-NC-ND 4.0) License. 